\title{
Openness and access of learners with disabilities in the department of adult education: challenges and prospects
}

\begin{abstract}
The paper explored challenges and prospects of openness and access of Higher Education Institutions (HEIs) to learners with disabilities. The aim was to determine the level of inclusivity of the Adult Education Department towards learners with disabilities. The objectives of the study were to: establish the extent to which the programmes in the department are open to all people; explore the extent to which learners have access to the programmes in the department and report about the learning experiences of learners with disabilities. Theories on Open Distance Learning (ODL) inclusion \& access for learners with Disabilities (LWD) provide a lens to understand and interpret data. The study assumed a qualitative approach and was underpinned by the intepretivist and advocacy paradigms. Semi-structured interviews were used to generate data from the participants. Data were analyzed using qualitative content analysis. The findings of the study indicated that as an institution the University of Swaziland (UNISWA) admission procedures lacked the aspect of allowing applicants to state their level of disability; programmes in the department were open and accessible to all people. Although accessibility for LWD was found to be happening; it was hampered by lack of infrastructure and resources for learners with visual disability. LWD felt that there was still room to orient academic staff and their colleagues on how they could assist them in their learning and university life. The study concluded that crafting of a policy to guide LWD learning was critical; it also concluded that programmes in the department were open and accessible to LWD; and that LWD needed infrastructure to support their learning which includes emotional support from staff and colleague. It is recommended that the department make policies and structural changes to promote access to students with disabilities. These include giving such learners additional time during tests and examinations, and the provision of separate exam rooms to allow for their freedom during such assessments. The authors recommend that HEIs thrive and aspire to be open and accessible to all citizens; which include learners with disabilities. It is also recommended that HEIs investment in infra-structural development of learning facilities, classrooms and laboratories and resource centre should take priority to support learners with disabilities
\end{abstract}

Keywords: inclusion, access, learners with disability (lwd), learner support
Volume 2 Issue 5 - 2018

\begin{abstract}
Nomazulu Ngozwana, Sindisiwe Maduna, David Jele, Lindiwe Ngcobo, Peles Biswalo Department of Adult Education, University of Swaziland, Swaziland
\end{abstract}

Correspondence: Nomazulu Ngozwana, Department of Adult Education, University of Swaziland, Kwaluseni Campus, Private Bag 4 Manzini, Swaziland, Email nomazulungozwana@gmail.com

Received:September II, 2018 | Published: October 04, 2018

\section{Introduction}

Swaziland is a small landlocked country that is situated between South Africa and Mozambique, with a population of about one million people of which the majority of about $70 \%$ live in the rural areas. People with disabilities form a substantial part of the poor majority of Swaziland and their human rights have been violated for the past times due to policies, programmes, practices and the attitude of other members of the society. Conditions of people with disabilities are worsened by their exclusion from the mainstream society ${ }^{2}$ thus resulting in the lack of equal access to health care, education, public facilities including buildings and transport, and employment opportunities to mention a few. When focusing attention on education, the early years of the twentieth century saw a movement towards educating students with special needs in an inclusive school environment (Ruijs, Van der Veen \& Peetsma, 2010) and towards meeting the basic learning needs of all people. This is where governments pledged to meet the educational needs of girls, people in poverty, ethnic minorities, and people with disabilities by 2015 (UNESCO, 2000). Additionally primary education was resolved to be accessible, free and compulsory and of good quality to all (UNESCO, 2000).
Furthermore, studies ${ }^{3}$ have shown that people with disabilities experience the worse socioeconomic outcomes and poverty than people without disabilities. Therefore disabled people tend to be overrepresented amongst the unemployed, the poor and the uneducated. Likewise, Eide \& Jele ${ }^{2}$ point out that the absence of comprehensive laws and policies in Eswatini to address people with disabilities' access to equal opportunities reflect a lack of political will and a failure to recognize disability rights as human rights.

The purpose of this paper explores the level of inclusivity of adult education department with its programmes, towards learners with disabilities. Specifically, the paper addressed the following objectives: to establish the extent to which the programmes in the department are open to all learners; to explore the extent to which learners with disabilities have access to the programmes offered in the department; to report about the learning experiences of learners, in particular their challenges and the future prospects. The following section will discuss the situation of people with disabilities in Swaziland just to provide a brief background to the study. That will be followed by discussing open distance learning and inclusion and access for learners with disabilities respectively. The methodology, findings, discussion will come before the concluding remarks. 


\section{Situation of people with disabilities in Swaziland}

The UN Convention on Rights of People with Disabilities (CRPD) (UN, 2006) defines disability as people who have long $\square$ term physical, mental, intellectual or sensory impairments which in interaction with various barriers may hinder their full and effective participation in society on an equal basis with others. Though, Living with a disability in Swaziland presents significant challenges. In 2007 Swaziland signed the United Nations Convention on the Rights of Persons with Disabilities (CRPD) $)^{1}$ and ratified it in 2012. Furthermore, the Constitution of Swaziland contains provisions directly addressing disability, as well as the EDSEC policy that speaks directly to the educational needs of people with disabilities. Nonetheless, Eide \& $\mathrm{Jele}^{2}$ reported that many people have the view that being around people with disabilities can bring bad luck. This therefore drives the relatives and family members to hide the disabled people in their families, thus denying them an opportunity to be involved in societal activities. These acts indicates what Leshota \& Sefotho ${ }^{4}$ outlined as the African ontology of disability, stating that people with disabilities occupy lower status than others in the category of humans and therefore are exempted from societal rites and other activities. The authors point out that in the African worldview, disability is viewed unwelcome and blows adversity and bad omen (2018:100). Probably that could be the reason why disabled people in Swaziland are hidden by their relatives and family members.

However the above mentioned cultural practices towards people with disabilities have since changed as a result of global realities and their influence packed with the ongoing interactions between the diverse societies. Swaziland has enacted The Persons with Disabilities Bill, in 2014 which caters for the general well-being of persons with disabilities. ${ }^{1}$ The bill will cater for concerns such as: to improve their socio-economic status; ensure equal access and opportunities to education, health and other services at all levels; promote inclusiveness; ensure that all buildings and infrastructure are accessible to persons with disabilities. It is therefore important to address the attitudes of society and the inaccessibility of the physical situation so that the integration of people with disabilities is spontaneous.

\section{Open distance learning (ODL)}

Open and Distance Leaning has experienced several paradigm shifts in the way it has been conducted for the past years. This is the mode of teaching and learning that gave opportunities and options for people coming from different angles who wanted to further their studies in a more flexible manner. ODL has been an alternative to traditional, campus-based class ${ }^{5}$ as it provides a second chance with the aim of closing the educational gap for its learners. ODL is also meant to address issues of inclusiveness by being open while offering educational opportunities to its learners. Thus the concept of open is widened towards education for all ${ }^{6}$ whereby open education has to interact with a surrounding society and consequently reach new target groups, in this case people with disabilities. ODL was earlier known as correspondence education during the time when it was mediated by mail, and is now currently replaced by technology-mediated learning known as e-learning or online learning (Ibid). Morolong ${ }^{5}$ further emphasize the importance of caring and support that needs to be put in place in order to improve learners' performance.

The idea about ODL is to remove barriers to education and allow learners to study according to their time, pace and place. In a conventional education system, learners need to attend daily lectures and be present in the campus. Therefore, for a working adult learner, this system will be difficult for them to study and work at the same time. However, in ODL, learners can work and further their education at the same time. Learners are also not required to travel for classes every day (Malaysian Qualifications Ageny, 2011). It is a type of learning mode whereby a teacher and student are separated by distance, but they may occasionally meet for tutorials (face to face sessions), which is what happens within the Adult Education Department of the University of Swaziland. Generally ODL adheres to characteristics such as flexibility in terms of age, content, status and educational background. The use of technology to mediate in ODL is active even though in some universities this needs further development ${ }^{5}$ as the use of technology is rather new, therefore ODL functions as a compliment to the traditional face to face instruction. This is actually the case with adult education department where adult learners attend parttime tutorial sessions but also use the available learning management system to access some materials, posted assignments and send their assignments as well. However, there are challenges faced by this ODL effort that include the lack of resources, unavailable relevant technology, lack of care and support system, policies and other regulations guiding ICT, need for structural resources among others. ${ }^{5}$ Nevertheless arguments by Letseka \& Pitsoe $^{7}$ indicate that ODL institutions provide access to education for working adults as well as enabling them to obtain their higher education qualifications.

\section{Inclusion and access for learners with disability (LWD)}

The inclusive and promotion of equitable and quality education for all is stated in goal 1 of the UN 2030 agenda (2015) while one of its subsections envisage the elimination of disparities and ensuring for equal access to all levels of education and training for all, including persons with disabilities. These 2030 goals are an extension of the Millennium Development Goals (MDG) that was supposed to be achieved by 2015 , even though the issue of disability was not surfaced. Only the 2010 MDG report mentioned disabilities, noting the limited opportunities facing children with disabilities, and the link between disability and marginalization in education. ${ }^{3}$ On the other hand, the UNESCO (2005) advocates for the rights-based approach inclusion to education that has principles such as 1) Access to free and compulsory education; 2) Equality, inclusion and non-discrimination and 3) The right to quality education, content and processes for all. However, there is no universally agreed definition of inclusive education, meaning that inclusivity is context-based. It is worth noting that the 2005 Constitution of the Kingdom of Swaziland provides in Chapter 3 for the protection and promotion of the fundamental rights and freedoms of all citizens. In Section 14(3) specific mention is made of disability where the Constitution says:

A person of whatever gender, race, and place of origin, political opinion, colour, religion, creed, age or disability shall be entitled to the fundamental rights and freedoms of the individual contained in this Chapter but subject to respect for the rights and freedoms of others and for the public interest.

Furthermore, the constitution also indicates issues of disability where it states that no person can be discriminated against on a number of grounds, including disability; and the rights of people with disabilities are realized. ${ }^{8}$ The constitution integrates well with the Swaziland EDSEC that clearly stipulates what is aspired regarding its commitment to inclusive, life-long learning, and further draws attention to issues of access, quality, equity, relevance, efficiency and delivery. ${ }^{9}$ Additionally the goal of EDSEC inclusive education is: to 
mainstream relevant, quality education for every learner, irrespective of gender, life circumstances, health status, disability, impairment, capacity to learn, level of achievement, financial status, or any other limiting circumstance (Ibid). While one of the objectives of inclusive education is to ensure that no one is denied their access to education at any level on the basis of disability.

In an effort to realize the goal and objectives of inclusive education in Eswatini, EDSEC mentioned strategies that include among others: ensure relevant teaching and learning materials are available for every learner, at every level; regulate and ensure that educational facilities are user-friendly for every learner; and to develop and facilitate capacity building programmes for teachers (The Government of the Kingdom of Swaziland, 2011). ${ }^{9}$

According to the study conducted by Dube \& Ongolo ${ }^{10}$ for the Secretariat of the African Decade for Persons with Disabilities (SADPD) for Swaziland context current challenges include the inadequate number of sufficiently trained teachers in the schools and issues of capacity where there are limited education personnel in the Ministry of Education to support the implementation process towards achieving the policy goals; and the lack of disability policy.

\section{Methodology}

The study used interpretive paradigm, a belief that people provide their own deep understanding of a concept and explores the understanding of the world in which they live using their subjective meanings of their experiences towards things. ${ }^{11}$ Moreover this is linked with advocacy paradigm, with its believe that inquiry needs to be intertwined with political and social issues. In agreement of this research should contain the agenda of reform that ultimately address the issues of empowerment, inequality, oppression, and domination. ${ }^{11}$ The study used the case study design and qualitative approach, to establish openness and access of learners with disabilities in the Department of Adult Education at the University of Eswatini. The case study design was appropriate because it enabled researchers to come to an understanding of the learners 'experiences using their perspectives regarding prospects and challenges felt.

Two learners with disabilities were purposively chosen for in-depth interviews using a semi-structured interview guide. All the learners have joined the Department of adult education. For triangulation purposes, a tutor was purposively interviewed as a key informant who also provides support to all learners with disabilities in the department. Even though age and gender were not considered important for this study, all the three participants were females.

Qualitative data analysis was done by reading the transcripts thoroughly and carefully as well as noting ideas; coding, reflecting on and writing thoughts in the margins next to the transcribed interviews (Burns and Groove, 2009) and themes and sub-themes were identified (Creswell, 2009) where similar ones were put in one category.

\section{Findings}

The findings of the study were intricate as the learners with disabilities shared their experiences well in accordance with the research questions. In an attempt to ascertain the extent to which the learners with disabilities had access to the programmes in the department of adult education, a number of questions were asked. Of particular interest, the questions meant to establish the extent to which adult education programmes were open to learners with disabilities.
The findings were presented under the following four categories: Openness of programmes to LWD; Access to programmes by LWD; Challenges faced by LWD; and Future Prospects suggested by LWD.

\section{Openness of the programmes to LWD}

This category had two themes being: the influence on choice of the university and the freedom to choose a programme of own choice. A learner with visual impairment was asked to indicate what influenced her choice of this university over others in the country or outside the country. The learner indicated that she wanted to do counseling in one school in Manzini, but ended up being forced to come to join UNISWA. She indicated that the school in Manzini could not admit her because of her disability and since they were not equipped for such assistance. The learner revealed that due to this failure to admit her by a Manzini school, her sponsor then recommended UNISWA as another option. This is what she said: I wanted to do counselling and I was forced to come here, it was not by choice and it was not my plan to come here. I wanted to go to one school in Manzini where I was told they were not prepared with braille. My sponsor told me to come and try UNISWA.

In addition, the researchers wanted to find out how the tutor perceived the programmes to be open and accessible for learners with visual/hearing/physical disabilities into the university. In response to this question the tutor indicated that UNISWA was at first inaccessible particularly for the visually impaired student but for the physically challenged students it was accessible. In explaining this point the tutor had this to say:

Before Delisile (Uniswa's first visually impaired student) it was difficult for visually impaired students to access UNISWA. But since the enrolment of Delisile UNISWA has put in place a number of things to support visually impaired student learning. The lecturers are now sensitized on how to deal with these students and they have managed to deal with Delisile. The lecturers were cooperative and supportive too.

This data indicates the extent to which UNISWA is open regarding its adult education programmes that admits and offer support to LWD. This is an indication that visually impaired students are not enough catered for by most educational institutions in the country. This may probably be because visually impaired students who went beyond high school had not been so many in the past, hence most educational institutions did not have provisions in terms of supporting such learners. ${ }^{12,13}$

Then, with regard to their freedom of choice of programmes, the learner with visual impairment indicated that she was read the pamphlet with the different programmes from which she chose adult education programme, which she ultimately joined. This is an indication that since she was visually impaired, the admission officers assisted her to choose the programme of her interest by reading out the different choices hence; she was free to decide which programme to take.

Subsequently, the tutor revealed that it was difficult for them particularly the visually impaired students to decide what they wanted to study because they find themselves channeled to certain programmes over others because they are forced by circumstances. In explaining this point the tutor had this to say: It is difficult because in most high schools the visually impaired students are forced to drop science subjects because of the shortage of qualified teachers for 
their conditions which results in these students having to do 5 or 6 subjects instead of 8 subjects which is done by the normal students. This reduces their passing chances, so they find themselves channeled to certain programmes only.

The above statement indicates that the students are disadvantaged by their disabilities over other students in their high school level, which is the one that dictates programmes to be taken at the higher levels.

Meanwhile, the visually impaired learner, who was the first to be admitted into adult education programme with a disability, continually, expressed gratitude concerning the lecturers who were always able to cater for her which was a result of the training they got during the orientation. In emphasizing this point she specified that:

Lecturers are able to cater for me through the training they received before they were engaged with me. If an opportunity come I can come back to do my diploma here, since I got a good treatment, I was supported and not discriminated.

This above data showed a positive aspect on the lecturers' part in facilitating learning among the visually impaired student. Given that she seemed to be happy about the means done by the lecturers in facilitating her education, a follow-up question was asked if she would recommend other visually impaired students to come to UNISWA. In response, the she said that she would gladly recommend UNISWA to other visually impaired students. In her own words: Yes, I would recommend UNISWA to other visually impaired students because learning is a good thing to keep your mind busy. As a first visually impaired student there were of course challenges I faced so I think the next student(s) will find things easier.

This was an indication that even though there were challenges faced by the visually impaired learner, the department of adult education was doing its best to make the institution open and accessible to the all. This indicates that even if this one graduates, this has opened gates for other students with similar disabilities to join the institution because the current student will highly recommend the institution to others.

\section{Access to programmes by LWD}

Learners were asked to indicate whether they have access to programmes that are provided in the department of adult education. This was also indicated in the themes: admission into the programmes, practices and policies that are in place to facilitate their access to education. There were mixed feeling pertaining to the issue of access. Another disabled learner who writes slowly as a result of the accident she had, echoed: Actually it depends on the disability a person has. Not all the learners are accepted in this university. I think the university looks at the disability. I think they may not take other people who cannot walk and are using wheelchairs. When I look at the corridors, the steps and other things, I don't think people on wheelchair can manage. For those who cannot see properly, they need to have someone to help them climb the steps/stairs. The deaf cannot be accepted because I have not seen anyone using sign language here.

The tutor had a different opinion regarding access for the physically disabled learners. She specified: For the physically challenged students it is easier for them to access the institution because they only need ramps for moving around the corridors and these are available for them, hence, a number of them are seen in the university corridors. Otherwise in terms of learning they do that like all other normal students.

However, the tutor further indicated that for the students with hearing problems it would be very difficult for them since they need people with special training and this was a countrywide problem because they even have problems in formal schools.

On another instance, a visually impaired learner said: They are trying. They told me that they are prepared for me and I must come but when I got here I found that they were not prepared but at least they are trying. The learners are friendly to me when learning through group discussions. Even the lecturers are also supporting me.

From the above two quotations, it is evident that there are challenges but the institution is trying and working hard to get things in order. It should be noted that the learner kept on saying "they," as an indication that she cannot really be sure of the specific people due to her condition. Pertaining to how they were admitted into the programme, it is worth noting that the application forms did not have a space for learners to indicate whether they were having disability or not. This is supported by the following expression: I applied in 2015 and was admitted. When they discovered my challenges they told me to wait for them as they were not prepared to take me as a blind person. They saw my condition when I came for orientation that year... In 2016 around April/May I got a letter from Admissions telling me to come and enroll.

The above statement indicate that there was no special admission criteria made for her, but she was admitted just like any other student, using her high school symbols to apply. However, the institution was not aware that she had the visual challenge, but only discovered after the admission. Therefore, she was returned back home while the institution was preparing for her. Clearly, that is an indication that the application forms do not give applicants the opportunity to indicate about their disability status. This is also an indication that for several years in the past, the institution did not have learners with special needs.

Still on the issue of access, LWD were asked to show any practices that they were aware of, which facilitate their access to education. In responding to this question the visual impaired learner mentioned orientation, brailing all educational materials and being given extra time for tests and exams as some of the practices that facilitated her access to education. From the response it was clear that this learner believed that people dealing with this type of disability needed to be taught on how to teach, care and deal with their challenges in order to facilitate for their smooth education. The student had this to say: During orientation, they invited a special guest from the special education school who is someone knowledgeable about disability to facilitate to other students and lecturers about this disability. They are trying to help other students know about disability.

As a student in the institution I am given the privilege of writing alone be it a test or exam as I need extra time so they add more time by giving me 30 minutes on top of a 1 hour paper. Even my educational materials are brailed before they give them to me so that I can read and write.

This finding indicates that the student was content with the practices the department is offering to her and this facilitates her access to education. Moreover, the department network with external guests from special education school to come and orient both learners 
and lecturers on how to handle people with disabilities. Yet another learner with slow writing disability submitted that: I was asked to provide evidence that I have the disability then I produced doctor's report to confirm my status of accident. During exams they add 15 to 20 minutes extra time to give me the chance to finish writing because I am very slow. I cannot write fast. That helps but not that much. During the class tests, I am not given extra time, instead I write within the allocated time. I do not finish and therefore I end up failing the tests. That was different from what happened during exam as they required a letter... During my first year I was made to sit in a different room with another student having a visual disability.

The same learner experienced a different situation in her second year. This is what she said: During my second year, I was mixed with other normal students. At the end of the allocated time for the paper I was told to stop writing and they took my script. I tried to explain my situation but the invigilator told me that they were not aware as no one has said anything to them. Then I was chased [from the exam venue] When I was out with other students someone called me to come back to the exam room. I was then told to sit down and continue to write but then I was no longer focused... I actually felt discouraged and I felt like not to continue but to drop out from the programme. The University was very harsh last year.

It is clear that the learner's disability is not visible or easily seen by mere looking at her, which poses a lot of challenges towards her accessibility to education. On the issue of policies that are in place in order to facilitate for their access to education, all the learners indicated that they were not aware of any. Only the tutor responded by saying, "There are no policies at the moment. Even in government the bill has not yet passed at the parliament, it is still work in progress." Clearly, there are no policies in place yet, but this means that documents are there, showing that policy development is still work in progress in the country, let alone in the institution.

\section{Challenges faced by LWD}

The learners were asked to indicate the challenges and/or problems they encountered during their study. In response they indicated several challenges that incorporate lack of resources such as un-brailed books in the library, shortage of computers with JAWS software and the absence of the support unit for LWD. In emphasizing these challenges the visually impaired said: As a student in the institution you are expected to do research on your own but for me it is difficult because I cannot go beyond the lecturers' notes since the library does not have books with braille. Again it is difficult to surf the internet because there are no computers with JAWS software which enables the computers to talk so that I can also be able to use information for my research. A student support unit would also be helpful to students like me because we can get the necessary help from the unit.

The above thoughts regarding the challenges were also supported by their tutor. Subsequently, the learner who is writing slowly and disabled added: I am challenged because I need to tell each and every lecturer about my problems. Some of the lecturers understand but some do not accept as they don't understand. It is because no one can see my disability just by looking at me. I usually find myself as a problem [burden] and I sometimes keep quiet as I always feel stressful to be telling everyone. It would be better if HOD have told all the lecturers... The fact of being chased out of the exam room and then calling me again when I am out is very painful and embarrassing. Moreover, some students make fun of me, it's like I want favours from Lecturers [when I raise my challenges]. It is very painful to tell everybody about my challenges (she sighs...becoming emotional)... The other thing is that computers are not enough. So we wait for each other. For me, time is not enough when I use the computer because I am not fast, so other students cause trouble; they complain that I am taking more than enough time while they have been long waiting. I cannot be as fast as they are. Maybe computers for the disabled people should be put separately so that we can use them freely.

The data reveals the challenges faced by these LWD. These are real concerns that need to be addressed by the institution. This also shows that the use of technology extends to everyone including people with disability and seemingly developing.

\section{Future prospects}

The learners were asked to suggest ways in which current policies and practices can be improved to facilitate access for learners with disability. Several things were mentioned here, such as brailing of library books, installation of JAWS software and to encourage other students to support the disabled students. A learner who was passionate in the brailing of library books and the installation of JAWS software emphasise that; I suggest that for visually impaired students to perform better the institution should try to braille other books in the library as they have a lot of information. Computers should be installed with JAWS software and placed in the computer labs which will make us to be able to use them because the software enables the computers to talk to us, so we will be able to use the internet. This can be very helpful since we cannot all afford to have laptops.

The student further indicated that: During orientation, other students should be encouraged to support the disabled students. They should be told to show care, support and be concerned about the visually impaired students. People should offer help to us and we always appreciate if asked to be helped. If then we don't need help we will always indicate that we are comfortable.

Another learner expressed that: If I can make an example of myself, if the university say I should bring a letter, it should inform all the concerned people about my situation, to avoid the confusion where one person will know while the others do not know about me. ... I would suggest that the extra time be applied even in class tests, not only the exams. I also suggest to be separated from others and be placed in another venue when writing exams.

The tutor was asked to suggest ways in which the current policies and practices to enhance education for learners with disabilities could be improved. The tutor indicated that, a support unit would be a pillar for everything concerning the learning of the students if it can be established by the institution. She went on to state that the engagement of an assistant person who would help with editing the braille as the process takes a long time to do could help improve the current practices. Another improvement mentioned is to avail the JAWS software for installing in some computers in the library and the computer centre, which will be used by the students and availing brailed books in the library for the students to be in a position to read widely for enhancing their learning as opposed to the students relying on the notes provided by the lecturers.

The above findings calls for the institution to improve the services provided for these students and this could be done by the establishment of a support unit. Once this unit is established it would be easier for all the other things to be made available for supporting the students' learning. 


\section{Discussion}

The study discovered that the department of adult education was open to all learners who wish to enroll and further their studies in the field of adult education. The views from the participants revealed that they chose to join the adult education programme out of their own will and they received a considerable support from the department, which facilitated their smooth learning. The findings confirmed what Dalsgaard \& Thestrup ${ }^{6}$ stated regarding the availability of open education that has to interact with a surrounding society so that it reaches new target groups such as people with disability. This shows that UNISWA as an institution with its adult education department in particular is committed to the respect of difference and acceptance of people with disability as part of the larger diversity in the society.

Moreover the findings indicated that there was access to adult education programmes by learners with disabilities. The fact that the institution admitted learners with different disabilities is sufficient to show its access to all people regardless of their conditions of life. This was supported by the data that stated that all learners were admitted on the basis of their symbols as opposed to their disability condition. Moreover a tutor further specified that for physically challenged learners, access to the institution seemed easier because the ramps to assist with their movement are there in all the corridors. The above findings confirm what literature state ${ }^{5,7,8}$ regarding access and inclusiveness of all people within the ODL context. On the other hand, for learners with visual impairment, the findings have shown that they got support from both lecturers and other learners, which upholds what ${ }^{5}$ pointed out regarding the necessity of supporting and caring for learners in the ODL environment as opposed to those enrolled for traditional face to face instruction. The data revealed that learners are given braille notes and they are made to write the tests and exams in a separate venue where they can be also given extra time.

However, this was a different scenario with a slow writing learner who encountered challenges pertaining to her class tests and the second exam as she was mixed with other learners who are regarded normal. The data states that during tests, the learner is not given extra time and she fails because she cannot finish writing. Additional challenges were further mentioned by the visually disabled learner to be books without braille in the library, lack of JAWS software in the computers as there were none that were ear-marked for learners with disabilities. These experiences support literature ${ }^{5,10}$ that reveal several challenges of lack of resources, unavailable relevant technology, lack of care and support system, policies and other regulations, the need for structural resources and insufficient personnel to provide the necessary support for people with disability. However, in spite of these conditions, the learners continued to advance within their programmes with the little support they got from the tutor and other lecturers.

The data revealed that the establishment of a support service unit for learners with disability could bring a lot of changes and improvement for LWD and therefore could facilitate for their effective learning. Another thing would be to increase an additional person to serve as an assistant tutor who can edit and braille notes and other materials for the visually impaired learners. This is corresponding to EDSEC policy and the current draft Bill that are striving for, regarding future prospects for people with disabilities in Swaziland. ${ }^{1,9}$ The policy documents aspire to remove all restrictive environment and all barriers that can hamper the development of people with disability towards attaining their educational goal. ${ }^{14,15}$

\section{Conclusion}

This paper illustrated that the department of adult education is open and transparent in offering programmes to all people alike, including the minority population of people with disabilities. This notion also highlights that learners with disability freely access educational information from both lecturers and other learners through group discussions and braille materials to enhance their learning. This means that inclusive education is realized by the University of Swaziland even though there are no specific policies in place, only the practices. The department is in partnership with other external people from special education school, who come and orient both learners and lecturers on how to handle learners with disabilities.

On the basis of the findings, it is recommended that: 1) Favorable policies for LWD need to be developed by the department and should entail additional time given to learners during tests and examinations; and the provision of separate exam rooms need to be there as to allow for learners freedom during such assessments. 2) Additionally, institutions of higher education like UNISWA are encouraged to invest in infrastructural development of learning facilities, laboratories and resource centers, which will be top priority towards serving and supporting learners with disabilities.

\section{Acknowledgments}

None.

\section{Conflict of interest}

Author declares there is no conflict of interest.

\section{References}

1. Mavundla SD. Country report: Swaziland. 3 African Disability Rights Yearbook, 2015. p. 245-264.

2. Eide A, Jele B. Living Conditions among People with Disabilities in Swailand. SINTEF: Oslo. 2011.

3. World Health Organisation \& World Bank. World Report on Disability: Summary. 2011.

4. Leshota PL, Sefotho MM. Philosophy of disability: African perspectives Sefotho MM, editor. Philosophy in education and research, African perspectives. Van Schaik Publishers: Pretoria. 2018.

5. Morolong BL. Distance education and the use of information and communication technologies: Ethical challenges. Sefotho MM, editor. Philosophy in education and research, African perspectives. Van Schaik Publishers: Pretoria. 2018.

6. Dalsgaard C, Thestrup K. Dimensions of Openness: Beyond the Course as an Open Format in Online Education. International Review of Research in Open and Distributed Learning. 2015:16(6):78-97.

7. Letseka M, Pitsoe V. The challenges and prospects of access to higher education at UNISA. Studies in Higher Education. 2014;39(10):1942-1954.

8. Dube B, Magagula A. The Law and Legal Research in Swaziland. Hauser Global Law Programme, New York University. New York: NYU. 2007.

9. Government of Swaziland. The Swaziland Education and Training Sector Policy. Mbabane: Government Printer. 2011.

10. Dube K, Ongolo T, Jele B. Study on Education for Children with Disabilities in Southern Africa. The Secretariat of the African Decade of Persons with Disabilities (SADPD), Pretoria. 2012.

11. Rahi S. Research Design and Methods: A Systematic Review of Research 
Paradigms, Sampling Issues and Instruments Development. Int $J$ Econ Manag Sci. 2017;6:403.

12. Holmberg. Theory and practice of distance education. New York, NY: Routhledge. 1995.

13. Moore M, Moore MG. Towards a theory of independent learning and teaching. Journal of Higher Education. 1973;44:661-679.
14. Peters O. Understanding distance education. In: Harry K, John M, editors. Distance education: New perspectives. (10-18). London, UK: Routledge. 1993.

15. Yuen Yee Wong, Jing Zeng, Chun Kit Ho, et al. Trends in open and distance learning research: 2005 vs 2015. Asian Association of Open Universities Journal. 2016;11(2):216-227. 